\title{
Autoregressive Integrated Moving Average (ARIMA) Sebagai Model Peramalan Kasus Demam Berdarah Dengue
}

\section{Autoregressive Integrated Moving Average (ARIMA) As A Forecasting Model For Dengue Hemorrhagic Fever}

\author{
Roro Kushartanti ${ }^{a}$, Maulina Latifah ${ }^{\mathrm{b}}$ \\ Sekolah Tinggi Ilmu Kesehatan HAKLI Semarang, Indonesia
}

\section{A B S T RA C T/ A B S T RA K}

\begin{abstract}
ARIMA is a forecasting method time series that does not require a specific data pattern. This study aims to analyze the forecasting of Semarang City DHF cases specifically in the Rowosari Community Health Center. The study used monthly data on DHF cases in the Rowosari Community Health Center in 2016, 2017, and 2019 as many as 36 dengue case data. The best ARIMA model for forecasting is a model that meets the requirements for parameter significance, white noise and has the MAPE (Mean Absolute Percentage Error Smallest) value. The results of the analysis show that the best model for predicting the number of dengue cases in the Rowosari Public Health Center Semarang is the ARIMA model $(1,0,0)$ with a MAPE value of $43.98 \%$ and a significance coefficient of 0.353 , meaning that this model is suitable and feasible to be used as a forecasting model. DHF cases in the Rowosari Community Health Center Semarang City.
\end{abstract}

Keywords: Forecasting, ARIM; Dengue Hemorrhagic Fever

\begin{abstract}
ARIMA merupakan salah satu metode peramalan time series yang tidak mensyaratkan adanya suatu pola data tertentu. Penelitian ini bertujuan untuk menganalisis peramalan kasus DBD Kota Semarang secara khusus di wilayah kerja Puskesmas Rowosari. Peneitian menggunakan data bulanan kasus DBD di wilayah kerja Puskesmas Rowosari tahun 2016, 2017, dan 2019 sebanyak 36 data kasus DBD. Model ARIMA terbaik untuk peramalan adalah model yang memenuhi syarat signifikasi parameter, white noise dan memiliki nilai MAPE (Mean Absolute Percentage Error) terkecil. Hasil analisis menunjukkan model terbaik untuk peramalan jumlah kasus DBD di wilayah kerja Puskesmas Rowosari Kota Semarang adalah model ARIMA $(1,0,0)$ dengan nilai MAPE 43,98\% serta koefisien signifikansi sebesar 0,353, artinya model ini cocok dan layak digunakan sebagai model peramalan kasus DBD di wilayah kerja Puskesmas Rowosari Kota Semarang.
\end{abstract}

Kata Kunci : Peramalan, ARIMA, Demam Berdarah Dengue

Copyright $@ 2020$ Jurnal Kesehatan Lingkungan

All right reserved

*Alamat korespondensi : email : rorokushartanti@gmail.com

\section{PENDAHULUAN}

ARIMA (Autoregressive Integrated Moving Average) merupakan salah satu model peramalan yang secara penuh mengabaikan variabel independen, merupakan analisis dan peramalan data runtun waktu (time series). ARIMA dapat digunakan untuk peramalan jangka pendek, menengah, dan panjang, namun lebih tepat digunakan untuk peramalan jangka pendek. Model ini terdiri dari tiga langkah dasar yaitu tahap identifikasi, tahap penaksiran dan pengujian, dan penaksiran diagnostik. ARIMA merupakan penggabungan antara model AR (Autoregressive), I (Integrated), dan MA (Moving Average). ${ }^{1}$
Secara umum, model ARIMA ditulis dengan ARIMA (p,d,q) yang berarti model ARIMA terdiri dari derajat AR (p), derajat pembeda d dan derajat MA (q). Selain memiliki fungsi peramalan secara kuantitatif berdasarkan deret waktu, juga dapat menggambarkan perkembangan suatu kegiatan atau kondisi tertentu. ${ }^{2}$ Kondisi yang digambarkan bersifat umum, yang artinya dapat diaplikasikan pada bebagai fenomena berbeda seiring berjalannya waktu termasuk dalam bidang kesehatan masyarakat. Salah satu masalah kesehatan masyarakat yang patut menjadi perhatian adalah Demam Berdarah Dengue.

Penyakit DBD di Kota Semarang merupakan penyakit endemis dan sering menyebabkan Kejadian Luar Biasa (KLB). CFR 
DBD di Kota Semarang adalah 1,72\% (standar $<1 \%)$. Urutan IR terbesar di Kota Semarang yaitu Kelurahan Tembalang, Srondol Kulon, Karangrejo, Sampangan, Lamper Lor, Mijen, Brumbungan, Jomblang, Bongsari, dan Meteseh. ${ }^{3}$ Melihat perkembangan kasus DBD di Kota Semarang, serta fakta bahwa Puskesmas Rowosari yang wilayah kerjanya meliputi daerah endemis DBD, belum pernah dilakukan peramalan kasus DBD. Oleh sebab itu, perlu suatu metode peramalan untuk meramalkan jumlah kasus DBD pada tahun yang akan datang sebagai langkah preventif untuk mencegah terjadinya peningkatan kasus DBD. Data pengamatan jumlah kasus DBD dapat dilihat sebagai data time series. Data tersebut dapat disajikan melalui model ARIMA.
Penelitian ini menggunakan data sekunder yang menggunakan data bulanan jumlah kasus DBD yang tercatat dan dilaporkan di wilayah kerja Puskesmas Rowosari tahun 2016, tahun 2017, dan tahun 2019. Data tersebut digunakan pada model ARIMA untuk mendapatkan suatu model guna meramalkan jumlah kasus penyakit DBD di masa yang akan datang ${ }^{4}$.

Langkah-langkah analisis data terdiri dari tahap identifikasi model meliputi pemeriksaan stasioneritas data dan identifikasi model sementara; penaksiran parameter dan pengujian diagnosis meliputi uji kenormalan residual, uji white noise dan uji signifikansi parameter; serta tahap penerapan meliputi penerapan hasil peramalan dan evaluasi. ${ }^{5}$

\section{BAHAN DAN METODE}

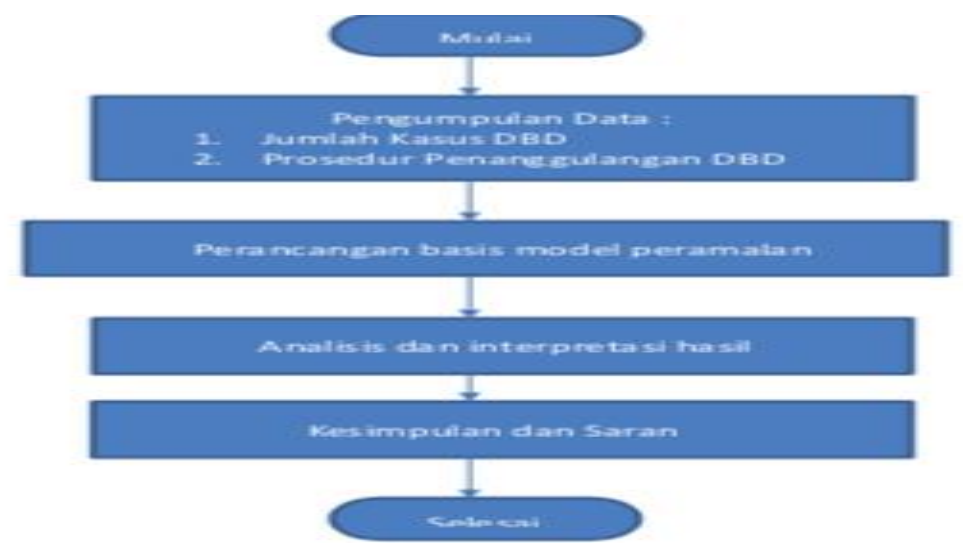

Gambar 1. Kerangka Kerja Penelitian

\section{HASIL}

Hasil analisis data penelitin dapat yaitu plot data jumlah kasus penyakit DBD di Puskesmas Rowosari Kota Semarang.
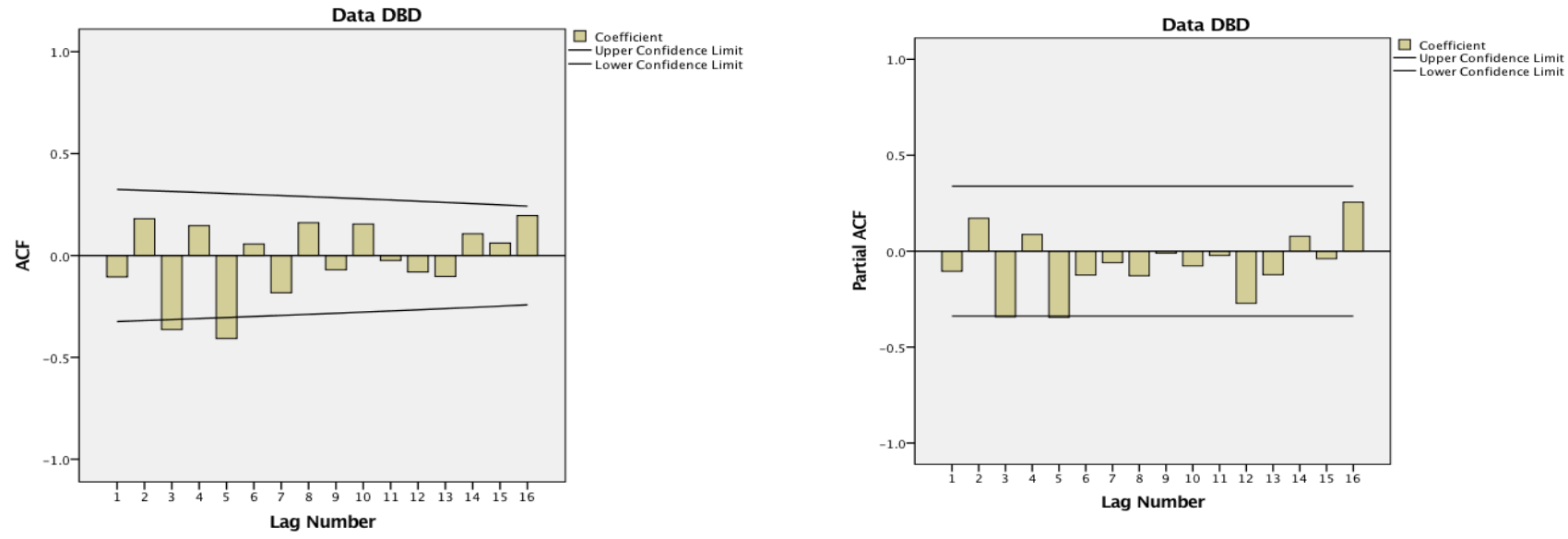

Sumber : hasil analisis data 
Gambar 2. Plot ACF dan PACF dan 36 Data Jumlah Kasus Penyakit DBD di Wilayah Kerja Puskesmas Rowosari yang Telah Stasioner

Plot data Gambar 2 menunjukkan bahwa pada plot ACF terdapat lag yang signifikan yaitu pada lag 1 dan 2 , begitu juga pada plot PACF terdapat lag yang signifikan yaitu pada lag 1 dan 2. Pola ACF dan PACF yang signifikan artinya bahwa dapat ditentukan model-model tentatif

ARIMA

Tabel 1. Peramalan data masing-masing model

\begin{tabular}{|c|c|c|c|c|c|}
\hline \multirow[t]{2}{*}{ No } & \multirow[t]{2}{*}{ Bulan } & \multicolumn{2}{|c|}{$(p, d, q)(1,0,0)$} & \multicolumn{2}{|c|}{$(p, d, q)(0,0,1)$} \\
\hline & & Data & Peramalan & Data & Peramalan \\
\hline 1 & Januari & 0 & 3,38 & 0 & 3,46 \\
\hline 2 & Februari & 4 & 3,35 & 4 & 3,42 \\
\hline 3 & Maret & 5 & 3,33 & 5 & 3,38 \\
\hline 4 & April & 3 & 3,31 & 3 & 3,34 \\
\hline 5 & Mei & 4 & 3,28 & 4 & 3,31 \\
\hline 6 & Juni & 2 & 3,26 & 2 & 3,27 \\
\hline 7 & Juli & 2 & 3,23 & 2 & 3,24 \\
\hline 8 & Agustus & 1 & 3,21 & 1 & 3.21 \\
\hline 9 & September & 6 & 3,18 & 6 & 3,17 \\
\hline 10 & Oktober & 4 & 3,16 & 4 & 3,14 \\
\hline 11 & November & 6 & 3,13 & 6 & 3,11 \\
\hline 12 & Desember & 4 & 3,11 & 4 & 3,08 \\
\hline \multirow[t]{2}{*}{ No } & Bulan & \multicolumn{2}{|c|}{$(\mathbf{p}, \mathbf{d}, \mathbf{q})(\mathbf{1}, \mathbf{1}, \mathbf{1})$} & & \\
\hline & & Data & Peramalan & & \\
\hline 1 & Januari & 0 & 3,38 & & \\
\hline 2 & Februari & 4 & 3,36 & & \\
\hline 3 & Maret & 5 & 3,33 & & \\
\hline 4 & April & 3 & 3,31 & & \\
\hline 5 & Mei & 4 & 3,28 & & \\
\hline 6 & Juni & 2 & 3,26 & & \\
\hline 7 & Juli & 2 & 3,23 & & \\
\hline 8 & Agustus & 1 & 3,21 & & \\
\hline 9 & September & 6 & 0 & & \\
\hline 10 & Oktober & 4 & 0 & & \\
\hline 11 & November & 6 & 0 & & \\
\hline 12 & Desember & 4 & 0 & & \\
\hline
\end{tabular}

Tabel 1 menjelaskan bahwa masingmasing model memiliki hasil prediksi yang hampir sama. Dari masing-masing model terdapat beberapa nilai yang hampir mendekati nilai data observasi, namun terdapat pula perbedaan nilai yang cukup jauh dengan data observasi, sehingga diperlukan perhitungan selanjutnya untuk mencari model yang paling efisien.

Penentuan model yang paling efisien dilakukan dengan cara mencari dahulu nilai kesalahan untuk masing-masing model, sehingga dapat ditentukan model mana yang paling baik. 
Jurnal Kesehatan Lingkungan

Vol.10, No.2, Oktober 2020, pp. $76-80$

ISSN 2615-188X(Online), ISSN 2089 - 0451(Print)

DOI: 10.47718/jkl.v10i2.1165

Journal homepage: https://ejurnal.poltekkes-manado.ac.id/index.php/jkl

Tabel 2. Validasi Kebaikan Model

\begin{tabular}{cccccc}
\hline No & ARIMA (p,d,q) & Estimasi Parameter & Nilai- $\boldsymbol{p}$ & MAPE & Nilai- $\boldsymbol{p}$ LJung Box \\
\hline 1 & $\mathbf{( 1 , 0 , 0 )}$ & $\mathbf{0 , 3 5 3}$ & $<\mathbf{0 , 0 0 1}$ & $\mathbf{4 3 , 9 8 \%}$ & $\mathbf{0 , 2 7 0}$ \\
2 & $(0,0,1)$ & 0,248 & 0,014 & $45,04 \%$ & 0,018 \\
3 & $(1,1,1)$ & 0,106 & 0,001 & $61,57 \%$ & 0,496 \\
\hline
\end{tabular}

Berdasarkan Tabel 2 maka diperoleh model terbaik dengan memenuhi prinsip signifikansi parameter mendekati 1 , kesalahan minimum (nilai MAPE terkecil) dan syarat white noise (nilai- $p>0,05$ ) yaitu model ARIMA $(1,0,0)$.

\section{PEMBAHASAN}

Hasil dari penelitian ini yaitu menentukan model ARIMA mana yang lebih cocok untuk digunakan pada data jumlah kasus penyakit DBD. Dari model yang sudah didapatkan, merupakan data mentah yang dijadikan sebagai input untuk masing-masing model untuk kemudian data prediksi tersebut dibandingkan dengan data observasi dengan melakukan uji kebaikan untuk melihat model mana yang lebih cocok, dan hasilnya merupakan data olahan hasil peramalan jumlah kasus di masa yang akan datang. ${ }^{6}$

Hasil uji kebaikan pada masing-masing model memiliki nilai $R$-square yang mendekati $1(<1)$, hal ini menunjukkan model time series dapat menjelaskan variabel jumlah kasus penyakit DBD secara signifikan dengan melibatkan observasi masa lalu. ${ }^{7} \mathrm{Hal}$ ini sesuai dengan hasil penelitian lain tentang peramalan jumlah penderita DBD di Kabupaten Jombang Jawa Timur dengan pendekatan fungsi transfer single input menyatakan bahwa terdapat kesamaan trend hasil peramalan dengan data aktual sebanyak $75 \%$ yaitu dikatakan signifikan atau valid. ${ }^{8}$

Nilai MAPE (Mean Absolute Percentage Error) atau ukuran kesalahan relatif yang terdapat pada hasil analisis merupakan angka persentase kesalahan hasil pendugaan/peramalan terhadap hasil aktual selama periode waktu tertentu. ${ }^{9}$ Nilai MAPE pada model ARIMA $(0,0,1)$ sebesar $45,04 \%$. Semakin kecil nilai MAPE maka semakin kecil kesalahan hasil pendugaan. Hasil suatu metode pendugaan mempunyai kemampuan peramalan sangat baik jika nilai MAPE $<10 \%$ dan mempunyai kemampuan pendugaan baik jika nilai MAPE 10-20\%. Residual pada model ini sudah bersifat acak. Hal ini dibuktikan dengan indikator Box L-Jung statistik yang memiliki nilai- $p>0,05$.

Hasil analisis peramalan mengenai jumlah kasus DBD di wilayah kerja Puskesmas Rowosari Kota Semarang menyatakan bahwa jumlah kasus berkisar 3-4 kasus tiap bulan, dan akan menurun di bulan September. Hasil ini dimungkinkan karena pada bulan September sudah memasuki musim kemarau, dan semakin meningkatnya kesadaran masyarakat akan pentingnya menjaga kebersihan sehingga populasi vektor nyamuk Aedes aegypti mulai berkurang. ${ }^{10}$

Metode Peramalan dengan menggunakan model ARIMA dapat diaplikasikan bagi Puskesmas guna mencegah terjadinya kenaikan insidensi atau Kejadian Luar Biasa terutama penyakit menular yang disebabkan oleh vektor.

\section{KESIMPULAN}

Berdasarkan hasil penelitian, untuk data prediksi jumlah kasus penyakit DBD dengan menggunakan model time series ARIMA berdasarkan nilai $R$-square dan nilai MAPE, model yang paling baik adalah model $(1,0,0)$.

ARIMA memiliki perfomansi yang baik untuk memprediksi jumlah suatu masalah di masa yang akan datang dengan durasi waktu jangka pendek, sebagai langkah preventif mencegah penyakit DBD.

\section{SARAN}

Bagi Puskesmas Rowosari Kota Semarang dan Dinas Kesehatan Kota Semarang diharapkan bisa menerapkan metode peramalan atau memberikan pelatihan khusus kepada staf yang terkait untuk bisa mengetahui prediksi jumlah kasus penyakit DBD di masyarakat guna mencegah peningkatan insidensi penyakit DBD terutama di musim penghujan dan mencegah terjadinya KLB (Kejadian Luar Biasa).

Bagi penelitian selanjutnya diharapkan dapat mencoba metode ARIMA dengan 
menggunakan software lain selain SPSS dan mengkombinasikan dengan variabel lain yang mendukung agar tingkat keakuratan hasil peramalan menjadi lebih baik.

\section{UCAPAN TERIMA KASIH}

Ucapan terima kasih diberikan kepada Kemristek_BRIN, Kepala Puskesmas Rowosari Kota Semarang beserta staf yang telah mendanai dan mendukung penelitian ini.

\section{DAFTAR PUSTAKA}

1. Makridakis spyros. 2013. Metode dan Aplikasi Peramalan. Jakarta : Erlangga.

2. Ali baroroh. 2013. Analisis Multivariat dan Time Series dengan SPSS 21, edisi I. Jakarta : PT Elex Media Komputindo.

3. Dinas Kesehatan Kota Semarang. 2017. Profil Kesehatan Kota Semarang Tahun 2017. Semarang : Dinas Kesehatan Kota Semarang.

4. Burhan bungin. 2013. Penelitian Kualitatif. Jakarta : Kencana Perdana Media Grup.

5. R Martinez, 2017. Geographic Information System for Dengue Prevention and Control. Scientific Working Group. Report on Dengue. 1-5 October 2016. Geneva, Switzerland, Copyright World Health Organization on behalf of the Special Programme for Research and Training in Tropical Disease. Diakses di : http://www.who.int/tdr/publications/public ations/swg_dengue_2.htm tanggal 15 Maret 2019.

6. F. N Hadiansyah. 2017. Prediksi Harga Cabai dengan Pemodelan Time Series ARIMA. Ind Journal on Computing. Vol.2, Issue I, Maret 2017. Pp 71-78.

7. A. Colin, et al. 1995. An R Squared measured of goodness of fit for some common non linear regressing models.

8. Soediono, Tito D. 2019. Peramalan Jumlah Penderita Demam Berdarah Dengue di Kabupaten Jombang Jawa Timur Dengan Pendekatan Fungsi Transfer Single Input. Jurnal Matematika, Statistika, dan Komputasi. Vol.15, No 2, 10-19.

http://journal.unhas.ac.id/index.php/jmsk

9. Willmatt J Cort dan Matsuura kenji. 2015. Advantages of the Mean Absolute Error (MAE) Over the Root Mean Square Error (RMSE) in Assessing Average Model Performance. Department of Geography. University of Daleware. Newyork, USA.

10. Ika Milasari. 2018. Peramalan Jumlah Penderita Demam Berdarah Menggunakan Model ARIMA Musiman (Studi Kasus di RSUD Kabupaten Sidoharjo. Skripsi. Jurusan Matematika, Fakultas Sains dan Teknologi. Universitas Islam Negeri Malang : Malang. 